\title{
Jessica Simpson (D)
}

City, University of London, UK

\section{Cassandra Smith}

Royal Melbourne Institute of Technology (RMIT), Australia

\begin{abstract}
How stigma is negotiated by female university students working in the sex industry remains under-researched and is limited to the context of erotic dancing. This article combines data collected in the UK and Australia with a total of I4 student sex workers and expands the scope by including individuals working in legal brothels, as independent escorts, webcammers and erotic dancers. Findings reveal that the use of the internet offered some women protection from discrimination, while at the same time exposing others to 'new' and intensified forms of stigma; which required alternative strategies to negate the negative effects. Despite the diverse nature of the sex industry, regardless of the sector, women in both countries were similar in their approach to sex work and their response to stigma. Given their relatively 'respectable' social standing, students were able to claim 'respectability' not available to all. Some women also shared an increased capacity to live openly as sex workers while simultaneously considering their engagement in the industry to be temporary. Rather than living a double life, respondents aspired to a singular, authentic selfhood. Close relationships were built with co-workers and many women felt a strong sense of rootedness within sex-worker communities, with sex work becoming an important part of their identity.
\end{abstract}

\section{Keywords}

Sex work, stigma, stigma management, students, university

\section{Corresponding author:}

Jessica Simpson, City, University of London Sociology Department, Rhind Building, Northampton Square, Clerkenwell, London ECIV OHB, UK.

Email: Jessica.Simpson@city.ac.uk 


\section{Introduction}

This article combines two sets of empirical data collected in the UK and Australia. Both studies explore how female university students, who do sex work, negotiate stigma. The two authors originally met as $\mathrm{PhD}$ candidates while presenting their respective findings at a sex-work research conference. There were substantial crossovers, which we felt required further exploration. Despite a wealth of existing literature on sex work and stigma management, we realised that there is a lack of research on students - as a unique demographic of sex workers - and their experiences of stigma within/outside the university setting. Previous research on the topic is limited to the USA and to students working as erotic dancers (Haeger and Deli-Amen, 2010; Trautner and Collett, 2010). This article expands current scholarship by providing a cross-national comparative analysis of university students in two different socio-cultural contexts and geographical locations (UK and Australia) and widens the focus to include students working in legal brothels, as independent escorts, erotic dancers and webcam models.

For the purpose of this article we draw on the work of Bowen and Bungay (2016: 187) who define stigma as:

... a socially constructed, context-specific experience of Othering that devalues one's identity, social contributions and potentially in ways that limit how one can interact within one's world of socio-structural relationships. Stigma is a social process embedded in discourses and relations of power wherein dominant groups use it to select, impose and reinforce their ideals about the ways in which others are allowed to be in the world.

Pheterson (1993) argues that through participation in sexual labour, women defy normative conceptions of female sexuality/femininity and threaten to destabilise heteronormativity, which determines the social ordering of sexual acts. Consequentially, sex workers are subject to 'whore stigma', which is characterised by hostile stereotyping, loss of status and social exclusion. Although the term 'whore' is commonly associated with women involved in 'prostitution', Benoit et al. (2015) found that the term and devaluation impacts all forms of sex work. Our research supports this finding as regardless of the sector they worked in, all respondents experienced whore stigma. However, the level and fear of stigma varied given that some forms of sex work are more heavily stigmatised than others (see Weitzer's (2009: 217) 'hierarchy' of sex work). In reference to Bowen and Bungay's (2016) definition, we also found that stigma was context-specific and experienced differently. For example, webcammers faced stigma online in ways that escorts and erotic dancers did not and this shaped the techniques employed to negotiate the negative effects. This supports arguments made elsewhere regarding the diverse nature of the sex industry and how there is no 'one' sex work(er) experience (Hardy, 2013). 
Nevertheless, a key finding from this article is that, regardless of the sector, participants adopted similar stigma management strategies and that this was typically, but not always, related to their status as students. Furthermore, while previous US-based studies found that students lived a 'double-life' by actively disassociating from all aspects of sex work, women in this research built close relationships with co-workers and became part of sex-worker communities. We argue that thanks to their more 'respectable' social standing as students and privilege in terms of race and class, respondents aspired to a 'single-self' (Bernstein, 2007) and possessed an increased capacity to 'come out' and to live openly as sex workers. While this was experienced positively on an individual level, we end the article by discussing how an influx of 'respectable' student sex workers could have potentially negative implications for sex workers more broadly.

\section{An overview of the changing nature of the sex industry and student participation in sex work}

Student participation in the sex industry is not a new phenomenon. Research has been carried out in the UK (Roberts et al., 2013; Sagar et al., 2015, 2016; Sanders and Hardy, 2013), Australia (Lantz, 2005), Canada (Sinacore et al., 2014), Germany (Betzer et al., 2015), the USA (Haeger and Deli-Amen, 2010; Trautner and Collett, 2010), and France (Duvall Smith, 2006). However, the topic is underresearched and predominately focused on students' trajectories into the sex industry. While there has been no research on the total number of student sex workers in Australia, estimates suggest between $10 \%$ and $40 \%$ of sex workers in legal brothels in Victoria, Australia are students (Groves et al., 2008; Maher et al., 2012; Pickering et al., 2009; Reilly, 2008). In the UK, recent estimates suggest that around one in 20 students engage in some form of sex work while at university (Sagar et al., 2015).

Existing research has found that students primarily enter the sex industry for financial purposes (Roberts et al., 2013). Yet, trajectories into sex work are often more complex and multifaceted (Colosi, 2010). Students also cite fun, flexibility, increased autonomy, the potential for higher income and fewer working hours (Sagar et al., 2016). From a structural perspective, Sanders and Hardy (2013) argue that the changing nature of the sex industry and a shift in social attitudes towards sexual labour are both interlinked to the reasons why students are now turning to sex work. This includes, the increased use of the internet by sex workers, the rise of digital sex work such as webcamming and the economic mainstreaming of strip clubs in the night-time economy, a space typically frequented by students. Indeed, Bernstein (2007) argues that the internet has created an environment which is more appealing to different sectors of the population. As a result, there has been an increase of middle-class, educated women and students, or at least not typically socially marginalised individuals, entering the industry as workers. The internet can offer a sense of privacy, protection and autonomy helping to eliminate feelings of shame traditionally associated with selling sexual labour. Scholars have argued 
that sex work has become both increasingly 'respectable' as well as professionalised through online and offline activism and advocacy. This enables workers to challenge dominant narratives surrounding their work (Bernstein, 2007; Feldman, 2014).

Despite such shifts, most research conducted on student sex work emphasises the negative role stigma continues to play. Sagar et al. (2015) found that students fear stigmatisation and the most important negative aspect of the work is the need to keep their involvement in the sex industry a secret. However, as secrecy and lies are common tactics employed by sex workers more generally, as a rational response to avoid stigma (Sanders, 2005), such techniques are not unique to students. There have been two key studies carried out in the USA looking specifically at student negotiations of sex-work stigma. From a social psychological perspective, Haeger and Deli-Amen (2010) carried out in-depth interviews in a City in South West America with seven women working in strip clubs and one woman working in the porn industry. The authors argue that students not only face stigma and stereotyping, they also experience cognitive dissonance between their sense of identity and beliefs on the one hand and their actions and engagement in the sex industry on the other.

Given the social stigma associated with working in the sex industry, it is not difficult to imagine that a college student sex worker could experience cognitive dissonance. Furthermore, even if women working in the sex industry did not feel it was degrading or in a contradiction with their morals, they could still experience cognitive dissonance from the threat of being stereotyped by others. (Haeger and Deli-Amen, 2010: 4-5)

Unsurprisingly, Haeger and Deli-Amen (2010) found all respondents experienced cognitive dissonance. As the quotation shows, their model is somewhat predeterministic. Regardless of whether or not students believed their actions contradicted their morals and values, the authors argued that respondents will experience cognitive dissonance as a result of the threat of stereotyping by others. The authors asked respondents how their engagement in sex work has affected their morals and values. This somewhat loaded and presumptuous question could lead participants to answer the question in a way which then allows the researchers to find 'evidence' of cognitive dissonance amongst student sex workers.

Taking a symbolic interactionist approach, Trautner interviewed 10 female university students working as topless dancers in the late 1990s in Austin, Texas. The data was analysed and published by Trautner and Collett (2010) over a decade later. The findings suggest that students are a unique demographic of sex workers as they are able to draw upon their positive, alternative and salient identity as students which neutralises the negative effects of stigma. Students in both Trautner and Collett (2010) and Haeger and Deli-Amen's (2010) studies lived a 'double-life' separating their student identity from their stripper role by actively distancing themselves from co-workers, customers and the stereotypical 'stripper lifestyle'. 
As students are considered to have (more) opportunities outside of the sex industry in comparison to non-students, Trautner and Collett (2010) argue that stripping was not considered a long-term facet of their lives. This assumed transience helped respondents to maintain a positive sense of self. However, it is important to remain critical of the latter argument given the lack of research on how/if students are able to leave sex work on completion of their degree. Hardy and Sanders (2015) found that many students in the UK continued stripping once they had graduated and found jobs outside of the industry to boost low income. As Trautner and Collett's (2010) study was carried out over 20 years ago, it is likely that the ways in which students experience and negotiate their work will have changed over time. Furthermore, by focusing on students who strip, those working in other sectors of a very diverse industry remain unstudied.

\section{Methods}

Through a sociological lens, the first of the two studies carried out by Jessica Simpson explored how female university students, working in different sectors of the sex industry, negotiated stigma in their daily lives. To recruit participants, Simpson created an advertisement that outlined the aims of the research, the procedure and demographic requirements. The advertisement was uploaded onto separate student and sex-worker online forums as well as different social media platforms. It was assumed that online methods would be appropriate as students in the UK tend to use both the internet and social media. Furthermore, that this method would have the potential to reach more students as the advertisement could be shared with relative ease. Admittedly, this method may exclude those who do not have access to/do not use social media or online forums; however, a certain form of exclusion is likely whatever strategy is used.

Nine women who were living and working in the UK took part in the research. Eight of the nine respondents self-identified as white and British and one respondent identified as white and East European. The age of interviewees ranged from 21-40 years old with an average age of 25. Four respondents self-identified as working class and five as middle class. Two respondents were undergraduate students, three postgraduate and four had graduated from university with an undergraduate degree. Three respondents worked as erotic dancers, three as independent escorts and three women worked as both glamour and webcam models simultaneously.

The second dataset comprises five female university students working in legal brothels in Victoria, Australia. From a health science perspective, Cassandra Smith focused on how respondents' university experiences are affected by their status as sex workers. Experiences in this sense included academic performance, interactions with university peers, academic staff and the university. Smith's study was considered important as there had been no research specifically on students who do sex work in Victoria since 2003 (Lantz, 2005). Respondents were aged between 20 and 30 years old. Four respondents self-identified as Caucasian one 
respondent identified as Jewish. Three respondents were undergraduate students and two were postgraduate. A personal network connection was initially used to provide access to student sex workers. This was followed by a snowball sampling method, which is a highly effective method when researching hidden and stigmatised populations (Renzetti and Lee, 1993).

Both authors conducted in-depth, semi-structured interviews from May to September 2015 and used a grounded theory approach to analyse their respective data (Strauss and Corbin, 1990). For the purpose of this article, each author independently read through the transcripts to ensure intercoder reliability. We recognise that the majority of respondents in both studies were female university students in a relatively privileged position as young, white, able-bodied, educated, cis-gender women, some also identified as heterosexual and middle class. This limits the conclusions we are able to make about how other students who do sex work, people of colour, transgender people and cis-gender men are able to negotiate stigma. Furthermore, as respondents self-selected to participate, such voluntary participation may be the result of altruism to change the perspective on sex work. This could mean that respondents have framed their work in a positive light.

\section{Australia versus the UK - higher education}

In Australia and the UK, university students are mostly female, white, and aged 30 years or younger (Department of Education and Training, 2018; HESA, 2019). Both studies in this article saw the majority of participants fall into these categories which meant that our respondents were also similar demographically not only to each other, but to university students generally. Secondly, as both the UK and Australian higher education systems have undergone neoliberal marketisation resulting in the rising cost of education and a reduction in government income support (Lantz, 2005; Sanders and Hardy, 2013) - it was likely that respondents will have shared similar experiences; as students in both countries are increasingly impoverished and turning to sex work as a pragmatic response (Roberts et al., 2010). Due to the marketisation of both HE systems, universities in the UK and Australia are more dependent on reputation than ever before in order to compete for students. Of the $236 \mathrm{UK}$ higher education and further education institutions which responded to a Freedom of Information request sent by Cusick et al. (2009), it was found that despite no reports of specific policies relating to student engagement in sex work, the majority of universities stated that students would face disciplinary action. Sex work is considered by such institutions to be a form of 'misconduct' which risks bringing the university into 'disrepute'. Although there is no comparable research in the Australian context, one respondent from Smith's research left her university when her peers and members of staff found out about her work. Women in both studies worked in secret as they had known other students who had been expelled, disciplined and publicly 'outed' as a result of their legal participation in the sex industry. Universities in the UK and Australia have been challenged on their attitudes and actions towards student 
sex work(ers). However, on the whole, they have had very little to say on the matter with most avoiding the topic completely (Sagar et al., 2016). Yet, without formalised policies to protect students in this context, it is likely they will continue to face discrimination and exclusion.

\section{Australia versus the UK - sex work}

The major difference of the studies was the legal settings. Full-service sex work was legalised at state level under the Sex Work Act 1994 licensing system in Victoria, Australia. While there are different models throughout Australia, ranging from criminalisation through to decriminalisation, in Victoria, brothels and independent full-service sex work are legal so long as the brothel or private sex worker has a license issued by the Business Licensing Authority, and brothels have local council approval for the venue. Other forms of full-service sex work, including street-based sex work and brothels without a license, are illegal in Victoria. Strip clubs are also legal, with strict rules surrounding the sexual services provided. In the UK, brothels are illegal, with full-service sex work being restricted to independent sex work. Strip clubs are legal, with similar provisions surrounding sexual services provided in them to Victoria, Australia. Webcamming is legal in both countries.

The difference in legality appears to have influenced the choices made by students who do sex work. Pickering et al. (2009: 23) state “... student workers are unlikely to be found in any part of the unlicensed sector as their youth makes them desirable workers, and they are able to attract good clientele in the licensed sector". Through this lens, we can see why students in Victoria may have chosen full-service sex work within legal brothels, but students in the UK chose independent escorting, stripping or webcamming, as this was the best legal option of sex work. Both researchers chose to undertake research with students working in the legal sectors as they were easier to access and because of ethical concerns of 'outing' students who may be working in the unlicensed sector of the sex industry. Further to this, Smith has a public health background where full-service sex workers are an over-researched population in areas relating to sexually transmitted infections and HIV (Donovan et al., 2012). Smith deliberately chose to work with full-service sex workers to counter this narrative and understand sexworker experiences outside of these public health measures.

\section{Ethical considerations}

Potential respondents had to be currently undertaking an undergraduate or postgraduate study in the UK (Simpson) or at a Victorian university (Smith), to be a current sex worker (in any sector for Simpson and in a legal brothel for Smith), to be 18 years old or over, and have adequate English skills to give informed consent. Ethical approval was obtained from the Sociology Department Ethics Committee at the City, University of London (Simpson) and Royal Melbourne Institute of Technology Health Sciences Human Ethics Sub-Committee (Smith). Peer-run 
sex-worker organisations the Scarlet Alliance and the Vixen Collective also provided letters of in-principle support for Smith's study.

Carrying out research with sex workers requires ethical consideration beyond institutional ethics approval. Sex workers are often suspicious of researchers due to poor treatment and the negative portrayal of sex work(ers) by some academics. Indeed, sex workers have stated that research does not benefit and can dehumanise sex workers (Jeffreys, 2010). Accordingly, individuals may question the researcher's stance on sex work prior to participating in the study (Begum et al., 2013). This information was freely given if asked of the researchers. The in-principle support from sex-worker bodies and peers who had previously participated helped to reduce the fear that we would misuse the information provided. Participants may also have identified with us as fellow university students rather than as researchers. This reduction in the typically unequal researcher-participant dynamic may have also helped to improve participant comfort levels.

\section{Discussion}

\section{Adopting a sex-worker identity}

Weitzer (2009) describes different types of sex work ranking them into a hierarchy based on price, third-party exploitation, risk of violence/victimisation, public visibility and impact on the community. The combined data suggested that the type of sex work shaped the level of stigma faced by women with full-service providers remaining the most stigmatised. The sector also shaped both the ways in which stigma was experienced and the techniques employed by women to negate the negative effects. However, unlike Weitzer's (2009) research, the stratification and boundaries appeared more blurred for respondents in this research with many women working in multiple areas of the industry, sometimes simultaneously.

I started in a brothel in South Melbourne as it was close to my house at the time, and then I did an apprenticeship at a dungeon which was out in the suburbs. I also worked at a strip club for a while too. (Paige, legal brothel worker, Australia)

Yet, regardless of the sector women worked in, all respondents in this research approached their work and negotiated stigma in similar ways. Research in the USA suggests that students actively distanced themselves from the stereotypical sex-worker identity/role and 'stripper lifestyle' - involving nights out, alcohol and substance use - and avoided forging relationships with co-workers and customers. It is argued that such 'coping strategies' allowed students to disassociate from the deviant identity and to buffer the negative effects of stigma (Haeger and Deli-Amen, 2010; Trautner and Collett, 2010). Alternatively, all 14 women in our combined study created close friendships with co-workers and became part of a sex-worker community in one way or another, again, regardless of the type of work they engaged in. For example, dancers enjoyed their work precisely because 
of the similarities sex work shared with their student lifestyle (involving nights out, drinking alcohol, flirting with men etc.)

It's just like a night out with the girls, you get ready you sit have a bit of a catch up with the girls... drink alcohol if you want to then you go have a flirt with some guys...the only difference is you take your clothes off [laughs]. (Hannah, erotic dancer, UK)

It's easy money and it's a lot of fun meeting new people all the time... we're allowed to drink so it's just like a night out, not like a normal job it's really good fun. You get to spend time with your friends, I love all the girls I work with, I really do love it. (Emily, erotic dancer, UK)

Students were able to neutralise stripping as 'fun' and 'just like a night out' as strip clubs have become increasingly normalised through processes of economic mainstreaming (Brents and Sanders, 2010; Colosi, 2010). As the stereotypical student lifestyle shares some similarities to their work, students may feel less of a need to separate the two worlds. This highlights how broader cultural changes can facilitate/shape how students negotiate their work within a stigmatised industry (Sanders and Hardy, 2013).

Respondents frequently used online forums to converse with their 'virtual colleagues' (Sanders et al., 2009) and some joined groups on social media platforms created for and used by student sex workers specifically.

Student sex work happens more than people think. I certainly know a lot of students who do it. There's a Facebook group that's only for sex workers which is great, you have to be approved to get on it and there's a lot of students on there. Probably $80 \%$ of them are students, masters or PhDs. (Sarah, independent escort, UK)

Previous research on how sex workers use the internet has tended to focus on independent escorts (Bernstein, 2007; Jones, 2015; Sharp and Earle, 2003) and more recently webcamming (Sanders et al., 2018). However, when recruiting participants for the study, Simpson found that sex workers across all sectors, including erotic dancers, are utilising the internet, that is, blogs, online forums and social media, as a means of facilitating community and solidarity.

Similarly, rather than distancing herself from other sex workers as suggested by researchers in the USA, Natalia (legal brothel worker, Australia) preferred that the majority of her friends also worked in the industry. Students in this study sought others who understood their experiences and shared a sense of collective grievance.

I tend to stick to the sex industry for $80 \%$ of my friends and if I haven't met them through the sex industry I've met them online where I can sort of, vet, how they'll view it [status as a sex worker] before I meet up with them. (Natalia, legal brothel worker, Australia) 
Sanders (2005) argues that women working in the sex industry often form special relationships borne out of stigma and secrecy. Trust is established as secrets can be shared, kept and support can be provided helping women to manage living with stigma. However, not all respondents worked in secret.

I used to lie and then it just sort of got too complicated. Now everyone, all of my friends know what I do, university don't know unless they ask what I do for a living and then I don't lie. I hid it from my old university, and it backfired when they found out, so honesty is the best policy. (Natalia, legal brothel worker, Australia)

Similarly, Cat actively disclosed her work to her peers (within and outside of the university context) as a strategy to manage potential stigmatisation. In doing so, she felt a sense of control in being able to educate others on what her job entails and to challenge negative assumptions.

I think because I was so open [at university] it didn't look like I was trying to hide anything and be seedy whereas if they [other students] had found out like a year in they'd of been like well why? What's wrong with what you're doing? Why didn't you tell us? You know 'cos I am so open I think it proves to people that there's nothing wrong with it... I'm really open with friends that want to ask questions I'd say ask questions 'cos you're probably like making up an answer in your head that's really out there and it's not like that at all. (Cat, Webcam model, UK)

Sanders (2005) goes on to argue that as sex work becomes a permanent feature of an individual's life, honesty becomes inevitable. Yet, as all 14 women considered sex work to be temporary and something that they chose to engage in while at university - often considering graduation to be the benchmark for when they would leave the industry - sex work was not necessarily considered to be a permanent feature of their lives which made 'coming out' inevitable. As identities are fluid, multifaceted and can change depending on one's social position such as when/if students leave the sex industry, assuming sex work is a transient part of their lives could help students in this context to relieve feelings of stigma associated with their work (Oselin, 2008; Trautner and Collett, 2010). Whether or not sex work is a short-term form of employment for students remains under-studied. Given the stigma and labelling associated with sex work, 'shedding' a 'deviant' identity can be difficult nonetheless and becoming a former sex worker does not necessarily remove the effects of stigma completely (Oselin, 2008). The majority of respondents were in a relatively privileged position as young, white, able-bodied, educated, cis-gender women, some also identified as heterosexual and middle class. Given their more 'respectable' social standing, they demonstrated a capacity to live openly as sex workers in ways not available to all sex workers. Techniques and one's ability to 'come out' in this context are, therefore, heavily shaped by class and race in particular. 
Rather than dividing their social worlds and living a double life, like the middleclass sex workers interviewed by Bernstein (2007), Natalia and Cat instead made efforts to achieve a more 'authentic' and singular sense of selfhood with no major divisions between the private and public. As a result of sex-worker rights activism and a shift in narratives of gender, there has also been a shift in attitudes towards sex work alongside an increased prominence of discourses around sex work as labour, or even empowerment (Jenness, 1990). Conceptualising sex work in more socially acceptable ways (i.e. as work) could also in part, help to explain why some students felt able to live openly as sex workers.

Research in the USA suggests that the assumed short-term nature of stripping allows students to maintain a positive sense of self as stripping was considered to be something students do or a role they play and not part of their identity (Trautner and Collett, 2010). Despite keeping her status as a sex worker hidden, Sarah felt that her work had become a central part of her identity.

... even though no one knows, [sex work is] a big part of my identity... I feel quite strongly rooted in escorting as well. I feel part of the community and I wouldn't want to leave it and not be a sex worker anymore...the stigma really bugs me, it really, really bugs me the way people talk about sex work and sex workers. It's not the clients that bug me, it's not the work that bugs me it's other people that really hurt my feelings and I'd love to not be a part of the stigma and secrecy. (Sarah, independent escort, UK)

Rather than disassociating from her job or considering it as merely a means to an end, Sarah actively engaged with the online sex-worker community so much so that her sense of rootedness within sex work could hinder her ability to leave the industry on completion of her degree. For some sex workers, technological advancements, particularly the rise and prominence of social media and other online platforms, has enabled sex workers to avoid stigma, isolation and to connect with one another with ease while protecting their offline identity (Jones, 2015; Sanders et al., 2018).

\section{'Blocking' online stigma}

To avoid stigma, sex workers commonly divide their social worlds by creating a 'manufactured identity' to protect their 'authentic' sense of self and as a business strategy (Sanders, 2005). Rather than creating a fake profile to protect their 'real' identity, students working as webcammers blurred their online/offline, personal/work persona by using their personal social media accounts as a marketing strategy to encourage potential customers to view their online content. In 2015, when the interviews for this article were carried out, respondents working as webcam models had accumulated a large following on social media. For example, Lucy had 77,300 followers on Instagram, Emily had 48,000 and on Twitter, Cat had over 10,000. Existing research, in most instances, points to the positive 
resources the internet offers sex workers such as increased privacy, autonomy and the elimination of shame (Bernstein, 2007; Jones, 2015). However, by using their personal social media accounts, respondents were not granted affordances such as increased privacy and instead, faced verbal (written) harassment and abuse online from a large number of people. Lumsden and Morgan (2014) argue that the internet can become a space where existing social issues are intensified. Respondents working as webcam models came to expect online hostility and considered it to be a direct part of their job.

I just think some people are like either insecure about themselves or jealous or are just being a complete troll, you're always gonna get people like that you just can't let them bother you... I just tend to block people straight away and report their accounts to make sure they don’t come back. (Emily, erotic dancer/webcam model, UK)

There are some nasty comments and like, it doesn't really bother me, you're gonna get it anyways, it's all part of what I do, it's part of the job and I expect it ... someone was giving me a load of grief so basically I print screened the comments and posted it and they got grief off my followers and they closed their account [laughs]. (Lucy, webcam model, UK)

As these quotations demonstrate, respondents were not passive recipients of stigma as they were able to retain a sense of control by blocking abusive users from accessing their profile page and were able to respond and challenge such messages online without fear of immediate physical violence. Respondents also received a large number of positive comments, messages of support and as their followers/ fans would also challenge hostility aimed towards them, this helped each woman to maintain a positive sense of self. Given the 'new' ways in which students experienced stigma, this sheds light on 'new'/alternative strategies of managing the negative effects.

\section{Displacing negative perceptions of sex work(ers)}

One important similarity our findings share with research in the USA is that all 14 respondents actively told customers, clients, or stated online that they were students (Trautner and Collett, 2010).

I always tell [customers] that I'm a student and not just a stripper ... I think men come into the club and think we're just these stupid bimbos that are desperate for money when in actual fact if you tell them you're studying they're actually quite surprised and think like 'oh my God' [laughs]. (Hannah, erotic dancer, UK)

By drawing on their socially accepted identity, students were able to present themselves as educated and not 'stupid bimbos'. Respondents also appeared to have options outside of the industry and were, therefore, not 'desperate for money'. 
Similar to Sanders' (2005) concept of the 'manufactured identity', applying Goffman's (1959) work on impression management and of the cynical performer, Colosi (2010) found that sex workers engage in a combination of four cynical acts, the ego boost, bimbo act, empty promise and pity plea, which play on heterosexual male erotic expectations of the 'stripper' identity. In contrast to the pity plea, involving the fabrication of a 'sob story' for money, or the 'bimbo act' where dancers perform playful almost childlike gestures and 'dumb' themselves down, by presenting themselves as students/educated, respondents appeared to play out the opposite of such acts.

The bimbo act and pity plea are acted out by dancers to manipulate the emotions of customers allowing them to believe they are in a position of superiority, intellectual and otherwise. By drawing on one aspect of their 'authentic' self/life/ identity rather than on a 'manufactured identity' of what customers are expecting, in contrast to respondent's in Colosi's (2010) research, students attempted to gain a sense of parity or even superiority, depending on the customer. This technique helped to shape how students are perceived by others, reducing feelings of devaluation. Importantly, this does not mean that the performance is not cynical in the same way as respondents disclosed their status as a student as a business strategy. For example, Sarah (independent escort, UK) stated 'I always tell clients I'm a student, it definitely sells'. By associating their 'positive' attribute (Link and Phelan, 2001) of student, the women were able to manage the loss of status and work towards nullifying discrimination that sex workers face. This demonstrates how students are in a unique position to negotiate stigma as they have a capacity to displace negative stereotypes. While claiming 'respectability' can have a positive effect on an individual level (Skeggs, 1997), the notion of an 'idealised' student sex worker' also has the potential to further stigmatise non-students perpetuating rather than challenging existing classed and racialised hierarchies among sex workers.

\section{Conclusion}

The aim of this article was twofold. Firstly, to explore how students involved in different areas of the sex industry - including full-service sex work, erotic dancing and webcamming - negotiate stigma associated with their work. Findings support existing research which highlights how student sex workers are not a homogenous group and stigma is not a uniform process. Depending on the type of sex work, students faced different levels and forms of hostility. This was most noticeable between independent escorts and webcammers as the former were able to utilise the internet as a means of avoiding stigma - through increased privacy and the protection of their offline identities - whereas the latter group were not granted such affordances and faced stigma as a result of their open and public use of the internet for work purposes.

The second aim of this article was to provide a cross-national comparative analysis of female student sex workers in the UK and Australia. Irrespective of 
the job type or geographical location, respondents shared important commonalities relating to their engagement with sex work and their negotiations of stigma. For example, while the legality of different types of sex work may shape the sector students work in, students forged close relationships with co-workers and felt a strong sense of rootedness within the sex-worker community which for some women became a part of their identity even when their work remained hidden. This finding challenges US-based research by Trautner and Collett (2010) and Haeger and Deli-Amen (2010), however, given that the former study was conducted in the late 1990s, the latter published in 2010, it is not surprising that student experiences in this context have shifted over time and place; particularly as technology, societal responses and discourses surrounding sex work have also progressed. The internet and social media in particular played a key role in helping students to maintain a positive sense of self and solidarity with other sex workers. Based on their relative social privilege, some women may have felt more able to 'come out' while simultaneously considering their engagement in the industry to be temporary. The findings across the two countries support Bernstein's (2007) argument that increasingly, middle-class sex workers are aspiring to a more 'authentic' and singular sense of selfhood - rather than traditional double self/life associated with sex work - with no, or fewer, divisions between the personal and public through a search for authenticity.

This research adds to the small but growing body of scholarship regarding student sex work by emphasising the unique position students occupy in contrast to non-student sex workers, which could offer some respite from the negative effects of 'whore stigma'. At the same time, by virtue of being a sex worker, findings demonstrate how students also potentially face unique forms of institutional discrimination at university in comparison to non-sex-working students. This highlights the need for higher education institutions across the globe to respond to the issue of student sex work to ensure that students are no longer punished, expelled or bullied for their work which is usually, and ironically, paying for their education.

While acknowledging each individual woman's own acts of resistance to the stigma they face on a daily basis - highlighted throughout this article - taking a wholly individualistic approach to understanding stigma management can in turn place the onus on marginalised individuals and communities. Such individuals are then expected to be resilient, to resist and employ coping strategies to manage whore stigma. Rather than considering the stigmatisation of sex workers and the material consequences, such as violence and exclusion, to be inevitable, it is important to continue to challenge political and other discourses on sex work which shape the ways in which sex workers are viewed and subsequently treated in society. Building respect for sex workers through human and worker rights is essential to counter prevailing and persistent stigma. Importantly, respect in this context cannot be conditional and limited to 'idealised' sex workers. For example, students were able to negotiate stigma by drawing on their socially valued student status. On an individual level, this was experienced positively and considered to be 
successful. However, more broadly, the notion of a 'respectable' sex worker also has the potential to inadvertently exacerbate existing classed and racialised hierarchies among sex workers which could render such stigma management techniques potentially harmful for non-students working in the sex industry who are unable to adopt the same strategies. Accordingly, this article has opened up questions for future research regarding the potential impact an influx of students has had or could have on other, less privileged sex workers.

\section{Acknowledgements}

Both authors would like to sincerely thank the women who have taken part in this research.

\section{ORCID ID}

Jessica Simpson (D) https://orcid.org/0000-0001-5144-358X

\section{References}

Begum S, Hocking JS, Groves J, et al. (2013) Sex workers talk about sex work: Six contradictory characteristics of legalised sex work in Melbourne, Australia. Culture, Health \& Sexuality 15(1): 85-100.

Benoit C, McCarthy B and Jansson M (2015) Stigma, sex work, and substance use: A comparative analysis. Sociology of Health \& Illness 3(3): 437-451.

Bernstein E (2007) Sex work for the middle classes. Sexualities 10(4): 473-488.

Betzer F, Köhler S and Schlemm L (2015) Sex work among students of higher education: A survey-based, cross-sectional study. Archives of Sexual Behaviour 44(3): 525-528.

Bowen R and Bungay V (2016) Taint: an examination of the lived experiences of stigma and its lingering effects for eight sex industry experts. Culture, Health \& Sexuality 18(2): 184-197.

Brents BG. and Sanders T (2010) Mainstreaming the sex industry: Economic inclusion and social ambivalence. Journal of Law and Society 37(1): 40-60.

Colosi R (2010) 'Just get pissed and enjoy yourself': Understanding lap-dancing as 'Anti work'. In: Hardy K, Kingston S and Sanders T (eds) New Sociologies of Sex Work. Farnham: Ashgate Publishing Limited, pp. 167-180.

Cusick L, Roberts R and Paton S (2009) Higher and further education institution policies on student and staff involvement in commercial sex. Journal of Higher Education Policy and Management 31(2): 185-195.

Department of Education and Training (2018) 2017 Student summary (D18/662305). Canberra, Australia: Department of Education and Training.

Donovan B, Harcourt C, Egger S, et al. (2012) The Sex Industry in New South Wales: A Report to the NSW Ministry of Health. Sydney: Kirby Institute, University of New South Wales.

Duval Smith A (2006) 40,000 French students join sex trade to fund degrees, The Independent. Available at: https://www.independent.co.uk/news/world/europe/th ousands-of-students-join-sex-trade-to-fund-degrees-422287.html (accessed 1 September 2016). 
Feldman V (2014) Sex work politics and the internet. In: Showden CR and Majic S (eds) Negotiating Sex Work: Unintended Consequences of Policy and Activism. Minneapolis: University of Minnesota Press, pp. 243-266.

Goffman I (1963) Stigma. Englewood Cliffs, NJ: Prentice-Hall.

Groves J, Newton DC, Chen MY, et al. (2008) Sex workers working within a legalised industry: Their side of the story. Sexually Transmitted Infections 84(5): 393-394.

Haeger H and Deli-Amen R (2010) Female college students working in the sex industry: A hidden population. NASPA Journal About Women in Higher Education. 2(1): 4-27.

Hardy K (2013) Equal to any other, but not the same as any other: The politics of sexual labour, the body and intercorporeality. In: Wolkowitz C, Cohen RL, Sanders T, et al. (eds) Body/Sex/Work: Intimate, Embodied and Sexualised Labour. Basingstoke: Palgrave Macmillan, pp. 43-58.

Hardy K and Sanders T (2015) The political economy of 'lap dancing': Contested careers and women's work in the stripping industry. Work, Employment and Society 29(1): $119-136$.

Higher Education Statistics Agency (2019) HESA student record 2017/18. Chichester: Higher Education Statistics Agency Limited.

Jeffreys E (2010) Sex worker-driven research: Best practice ethics. Challenging Politics: Critical Voices. Available at: https://www.nswp.org/resource/sex-worker-drivenresearch-best-practice-ethics (accessed 1 December 2016).

Jenness V (1990) From sex as sin to sex as work: COYOTE and the reorganization of prostitution as a social problem. Social Problems 37(3): 403-420.

Jones A (2015) Sex work in a digital era. Sociology Compass 9(7): 558-570.

Lantz S (2005) Students working in the Melbourne sex industry: Education, human capital and the changing patterns of the youth labour market. Journal of Youth Studies 8(4): 385-401.

Link B and Phelan J (2001) Conceptualizing stigma. Annual Review of Sociology 27(1): 363-385.

Lumsden K and Morgan MH (2014) 'Fraping', 'Trolling' and 'Rinsing': Social Networking, Feminist Thought and the Construction of Young Women as Victims or Villains. Available at: https://dspace.lboro.ac.uk/dspace-jspui/handle/2134/15756 (accessed May 2015).

Maher J, Pickering S and Gerard A (2012) Sex Work: Labour, Mobility and Sexual Services. Abingdon: Routledge.

Oselin SS (2009) Leaving the streets: Transformation of prostitute identity within the prostitution rehabilitation program. Deviant Behavior 30(4): 379-406.

Pheterson G (1993) The whore stigma: Female dishonor and male unworthiness. Social Text 37(winter): 39-64.

Pickering S, Maher J and Gerard A (2009) Final Report To Consumer Affairs Victoria: Working in Victorian Brothels. Melbourne: Consumer Affairs Victoria, Victorian Government.

Reilly T (2008) Students turn to sex work to help pay for university. The Age. Available at: https://www.theage.com.au/national/students-turn-to-sex-work-to-help-pay-for-universi ty-20080302-ge6slm.html (accessed 1 September 2016).

Renzetti CM and Lee RM (1993) Researching Sensitive Topics. Newbury Park, CA: SAGE.

Roberts R, Jones A and Sanders T (2013) Students and sex work in the UK: Providers and purchasers. Sex Education: Sexuality, Society and Learning 13(3): 349-363. 
Roberts R, Sanders T, Myers E, et al. (2010) Participation in sex work: Students' views. Sex Education 10(2): 145-156.

Sagar T, Jones D, Symons K, et al. (2015) Student participation in the sex industry: Higher education responses and staff experiences and perceptions. Journal of Higher Education Policy and Management 37(4): 400-412.

Sagar T, Jones D, Symons K, et al. (2016) Student involvement in the UK sex industry: Motivations and experiences. The British Journal of Sociology 67(4): 697-718.

Sanders T (2005) Sex Work: A Risky Business. Cullompton: Willan Publishing.

Sanders T and Hardy K (2015) Students selling sex: Marketisation, higher education and consumption. British Journal of Sociology of Education 36(5): 747-765.

Sanders T, O’Neill M and Pitcher J (2009) Prostitution: Sex Work, Policy and Politics. London: SAGE.

Sanders T, O'Neill M and Pitcher J (2018) Prostitution: Sex Work, Policy and Politics (2nd edn). London: SAGE.

Sharp K and Earle S (2003) Cyberpunters and cyberwhores: Prostitution on the internet. In: Jewkes Y (ed.) Dot Cons. Crime, Deviance and Identity on the Internet. Cullompton: Willan Press, pp. 36-52.

Sinacore AL, Beheshta J and Rezazadeh SM (2014) Female university students working in the sex trade: A narrative analysis. Canadian Journal of Counselling and Psychotherapy 48(4): 40-56.

Skeggs B (1997) Formations of Class and Gender. London: SAGE.

Strauss AL and Corbin J (1998) Basics of Qualitative Research: Techniques and Procedures for Developing Grounded Theory (2nd edn). Thousand Oaks, CA: SAGE.

Trautner MN and Collett JL (2010) Students who strip: The benefits of alternate identities for managing stigma. Symbolic Interaction 33(2): 257-279.

Weitzer R (2009) Sociology of sex work. Annual Review of Sociology 35: 213.

Jessica Simpson has a BA from Leeds Beckett University, an MA from the University of Essex and she is currently a $\mathrm{PhD}$ candidate in the Department of Sociology at City, University of London. Her research interests include the sex industry, gender, sexualities, class and identity. Jessica's PhD explores what happens after university for female students working in sex work and in 'mainstream' employment.

Cassandra Smith has a BPharm (Hons) from the University of Tasmania, a MPH from the University of Melbourne and she is currently a $\mathrm{PhD}$ candidate in the Global, Urban and Social Science School at Royal Melbourne Institute of Technology (RMIT). Her research interests are the sex industry, marginalised communities, gender and health. Cassandra's PhD explores how being a sex worker affects student educational experiences while at university. 